\title{
Multibreed genomic evaluations using purebred Holsteins, Jerseys, and Brown Swiss
}

\author{
K. M. Olson, ${ }^{\star 1}$ P. M. VanRaden, $†$ and M. E. Tooker† \\ ${ }^{*}$ National Association of Animal Breeders, Columbia, MO 65205 \\ †Animal Improvement Programs Laboratory, Agricultural Research Service, USDA, Beltsville, MD 20705
}

\begin{abstract}
Multibreed models are currently used in traditional US Department of Agriculture (USDA) dairy cattle genetic evaluations of yield and health traits, but within-breed models are used in genomic evaluations. Multibreed genomic models were developed and tested using the 19,686 genotyped bulls and cows included in the official August 2009 USDA genomic evaluation. The data were divided into training and validation sets. The training data set comprised bulls that were daughter proven and cows that had records as of November 2004, totaling 5,331 Holstein, 1,361 Jersey, and 506 Brown Swiss. The validation data set had 2,508 Holstein, 413 Jersey, and 185 Brown Swiss bulls that were unproven (no daughter information) in November 2004 and proven by August 2009. A common set of 43,385 single nucleotide polymorphisms (SNP) was used for all breeds. Three methods of multibreed evaluation were investigated. Method 1 estimated SNP effects separately within breed and then applied those breed-specific SNP estimates to the other breeds. Method 2 estimated a common set of SNP effects from combined genotypes and phenotypes of all breeds. Method 3 solved for correlated SNP effects within each breed estimated jointly using a multitrait model where breeds were treated as different traits. Across-breed genomic predicted transmitting ability (GPTA) and within-breed GPTA were compared using regressions to predict the deregressed validation data. Method 1 worked poorly, and coefficients of determination $\left(\mathrm{R}^{2}\right)$ were much lower using training data from a different breed to estimate SNP effects. Correlations between direct genomic values computed using training data from different breeds were less than $30 \%$ and sometimes negative. Acrossbreed GPTA from method 2 had higher $\mathrm{R}^{2}$ values than parent average alone but typically produced lower $\mathrm{R}^{2}$ values than the within-breed GPTA. The across-breed $\mathrm{R}^{2}$ exceeded the within-breed $\mathrm{R}^{2}$ for a few traits in the
\end{abstract}

Received September 30, 2011.

Accepted March 19, 2012

${ }^{1}$ Corresponding author: Katie.Olson@genusplc.com
Brown Swiss breed, probably because information from the other breeds compensated for the small numbers of Brown Swiss training animals. Correlations between within-breed GPTA and across-breed GPTA ranged from 0.91 to 0.93 . The multibreed GPTA from method 3 were significantly better than the current within-breed GPTA, and adjusted $\mathrm{R}^{2}$ for protein yield (the only trait tested for method 3) were highest of all methods for all breeds. However, method 3 increased the adjusted $R^{2}$ by only 0.01 for Holsteins, $\leq 0.01$ for Jerseys, and 0.01 for Brown Swiss compared with within-breed predictions.

Key words: dairy cattle, genomic prediction, multibreed

\section{INTRODUCTION}

Genomic evaluations of dairy cattle have been official in the United States since January 2009 for Holsteins and Jerseys and since August 2009 for Brown Swiss. Since that time, interest has been increasing in genomic evaluations from the smaller populations of US dairy breeds, and some breeds are already submitting genotypes for parentage purposes (Wiggans et al., 2012). Interest also exists in including crossbred dairy cattle in US genomic evaluations. Currently, US traditional evaluations of calving, yield, and health traits (Cole et al., 2005; VanRaden et al., 2007) include both purebreds and crossbreds in the same model, but US genomic evaluations are computed only within breed. Animals with genotypes that contain too many breed-specific alleles from another breed, such as firstgeneration crossbreds, backcrosses, and 3-breed crosses, do not receive genomic evaluations (G. R. Wiggans, Animal Improvement Programs Laboratory, Agricultural Research Service, US Department of Agriculture, Beltsville, MD,, personal communication).

Other researchers have investigated using more than one breed in the same genomic evaluation system. An across-breed genomic evaluation has been implemented in New Zealand (Harris and Johnson, 2010) in which the pure Holsteins, Holstein-Friesians, crossbreds, and Jerseys are used as an admixture for a training data set, 
and then the SNP estimates are applied to the validation data set regardless of breed of origin. Hayes et al. (2009) also reported results for Jerseys and Holsteins in which 2 different methods were used. The first method applied SNP effects from the other breeds to the breed of interest and resulted in poor estimations and no gain in accuracy. The second method used all breeds as one population and was more accurate than parent average but not as effective as the within-breed analysis. Snelling et al. (2009) evaluated the USDA Meat Animal Research Center crossbred line using common SNP effects across breed but did not have sufficient numbers of each breed to estimate separate SNP effects.

Simulation studies have indicated that denser markers are needed before across-breed genomics is used on a wider scale (de Roos et al., 2008; Kizilkaya et al., 2010; Toosi et al., 2010). Early results from a high-density $(\sim 700,000$ SNP) study in New Zealand indicated no increase in the all-breed genomic prediction accuracy when the high-density chip was used; however, numbers of high-density genotypes for Jerseys were limited and the rest were imputed (Harris et al., 2011). These studies all investigated using single-trait methodology, where SNP effects were assumed the same in every breed.

Makgahlela et al. (2011) investigated multitrait genomic predictions in Nordic Red cattle by fitting an interaction of SNP effects with breed. They found little advantage to this method over treating the populations as homogeneous, but the authors suggested that the low accuracies might be due to the similarity in lines that were tested. Few or no other authors have applied multitrait methodology to genomic evaluations across breeds.

The objective of this study was to investigate 3 methods of genomic evaluation using purebred Holstein, Jersey, and Brown Swiss genotypes to predict independent daughter deviations. The 3 methods compared were (1) SNP effects estimated separately within each breed and then tested in another breed, (2) a common set of SNP effects estimated from combined genotypes and phenotypes of all breeds, and (3) correlated SNP effects within each breed estimated jointly using the multitrait model. These methods were validated along with parent averages (PA) using multiple regression to preserve the traditional within-breed information when testing the information added from other breeds.

\section{MATERIALS AND METHODS}

\section{Animals}

The animals were genotyped using the BovineSNP50 Genotyping BeadChip (Illumina, San Diego, CA), and all genotyped animals (proven) from the US Department of Agriculture (USDA) August 2009 genomic evaluation were included in the data set.

The data were divided into a training data set and a validation data set. The training data set included bulls that had daughter information and cows that had their own information by November 2004, including 5,331 Holstein, 1,361 Jersey, and 506 Brown Swiss animals of which 928,212 , and 40 were cows, respectively. The validation data included US proven bulls that had no daughter information in November 2004, but had daughter information in the August 2009 evaluation, and included 2,508 Holstein bulls, 413 Jersey bulls, and 185 Brown Swiss bulls. No known crossbred animals had been genotyped. A full pedigree was used for all 3 breeds; the Holsteins had 80,396 ancestors, the Jerseys had 17,243 ancestors, and the Brown Swiss had 4,682 ancestors in the pedigrees. Further analyses of the genotypes and relationships among breeds were presented in VanRaden et al. (2011).

The common set of 43,385 SNP (Wiggans et al., 2010) was used for all 3 breeds. The SNP had been chosen to (1) have a minor allele frequency of $>0.01$ in at least one breed, (2) have $<10 \%$ missing genotypes, and (3) have $<2 \%$ parent-progeny conflicts across all animals. Previous tests had revealed that reliabilities increased by $0.4 \%$ for Holsteins and $0.3 \%$ for Jerseys, and decreased by $0.2 \%$ for Brown Swiss when withinbreed predictions included all 43,385 SNP instead of excluding SNP with $<2 \%$ minor allele frequency (Wiggans et al., 2010).

\section{Methods}

Method 1 computed genomic evaluations of validation bulls in a given breed using SNP solutions from that same breed or from each other breed. The animals from a different breed contributed to the training data but not the validation data, whereas time separation was required within a breed to make the validation data independent of the training data. Therefore, the SNP solutions used from the other breeds were the solutions from the official USDA August 2009 genomic evaluation, whereas the within-breed SNP solutions used input data that would have been available in November 2004. The SNP estimates were calculated using a nonlinear model with a heavy-tailed distribution, which allowed SNP with smaller effects to be regressed toward zero (VanRaden, 2008).

Method 2 (across-breed) treated all breeds as the same population. The effects were estimated using all information from November 2004, with the base allele frequency estimated as a simple average rather than a weighted average of the base frequency for each breed. 
Thus, the across-breed base frequency was the sum of 0.333 times the Holstein, Jersey, and Brown Swiss base frequencies and should better estimate the true ancestral frequency before the breeds diverged than weighting by current population size. Base frequencies within each breed estimate the more recent allele frequencies of the earliest animals in the pedigree file. Withinbreed PTA were each converted to the Holstein 2004 base PTA using breed differences from the traditional evaluation, in which all breeds are compared directly in the same model. Additional adjustments were required for the 2005 base change because the all-breed evaluation was not implemented until 2007 (VanRaden et al., 2007). These across-breed PTA were then deregressed and used in computing genomic predictions.

Method 3 (multibreed) used a multitrait model with SNP effects in different breeds treated as correlated effects. Predictions were computed assuming that SNP effect correlations were the same for each breed pair; for example, 0.20 for each pair. Because of the computation required, only 3 levels of correlation were tested: $0.20,0.30$, and 0.55 . This method is similar to the multitrait across-country evaluation of genotypes described by VanRaden and Sullivan (2010) except breeds replace countries as the traits. The data included only purebred animals so their information contributed to only their respective breed; therefore, no correlation existed between residual effects in different breeds. If crossbreds were present in the population, the equations would need to be expanded by assigning SNP contributions according to breed composition so that records from crossbreds would not be double counted. An example on how to expand these equations to account for crossbreds is found in Makgahlela et al. (2011).

Mathematically, the 3 methods can be described using notation adapted from VanRaden (2008) as follows. Centered genotypes for the training animals of breed $i$ are in $\mathbf{Z}_{i}$. Genotypes are coded 0,1 , and 2 and centered by subtracting $2 p_{i}$, where $p_{i}$ is base frequency of the second allele in breed $i$, and then divided by the sum of $2 p_{i}\left(1-p_{i}\right)$ across loci. For breed $i$, the model contains unknown mean $\mathbf{b}_{i}$ with $\mathbf{X}$ defined as the column vector 1 , and the vector of SNP effects is $\mathbf{g}_{i}$ :

$$
\left[\begin{array}{cc}
\mathbf{X}^{\prime} \mathbf{R}_{i}^{-1} \mathbf{X} & \mathbf{X}^{\prime} \mathbf{R}_{i}^{-1} \mathbf{Z}_{i} \\
\mathbf{Z}_{i}^{\prime} \mathbf{R}_{i}^{-1} \mathbf{X} & \mathbf{Z}_{i}^{\prime} \mathbf{R}_{i}^{-1} \mathbf{Z}_{i}+\mathbf{K}_{i}
\end{array}\right]\left[\begin{array}{l}
\mathbf{b}_{i} \\
\mathbf{g}_{i}
\end{array}\right]=\left[\begin{array}{l}
\mathbf{X}^{\prime} \mathbf{R}_{i}^{-1} \mathbf{y}_{i} \\
\mathbf{Z}_{i}^{-1} \mathbf{R}_{i}^{-1} \mathbf{y}_{i}
\end{array}\right] .
$$

Matrix $\mathbf{K}_{i}$ is diagonal with diagonal elements related to marker variances that change across iterations due to the heavy-tailed prior as the size of SNP effects change. Matrix $\mathbf{R}_{i}^{-1}$ is diagonal with diagonals equal to daughter equivalents, and $\mathbf{y}_{i}$ is a vector of deregressed evaluations.

The DGV for validation animals in breed $j$ using SNP effects from breed $i$ are obtained as

$$
\mathbf{D G V}_{j}=\mathbf{b}_{i}+\mathbf{Z}_{j} \mathbf{g}_{i}
$$

Method 2 used the same math as method 1 except that the $i$ subscripts are removed because the $\mathbf{Z}_{i}$ are adjoined into one $\mathbf{Z}$ and all breeds contribute to estimating one $\mathbf{b}$ and one $\mathbf{g}$. Method 3 results in a larger system of equations to solve for all SNP effects simultaneously. The model is analogous to the multitrait model of VanRaden and Sullivan (2010), but the algorithm estimates SNP effects and sums these instead of including a genomic relationship matrix:

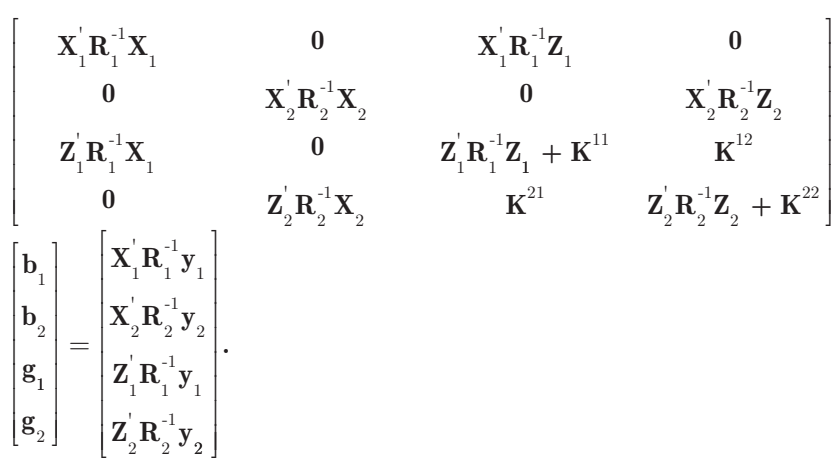

The equations are demonstrated for 2 breeds but are simple to expand to more breeds. Elements of $\mathbf{K}^{11}, \mathbf{K}^{12}$, $\mathbf{K}^{21}$, and $\mathbf{K}^{22}$ are the Kronecker product of $\mathbf{T}^{-1}$ with diagonal matrix $\mathbf{K}$, where $\mathbf{T}$ is the correlation matrix for SNP effects among breeds with all correlations assigned a common parameter value $(0.20,0.30$, and 0.55$)$.

The iterative method of VanRaden (2008) was used to solve the nonlinear equations. Methods 1, 2, and 3 did not include a polygenic effect because that was not included in the official USDA model at the time this research was conducted.

\section{Validation}

A multiple regression model that included an intercept, a regression on $\mathrm{PA}$, and a regression on DGV was used to predict the traditional evaluations of the validation bulls. An adjusted coefficient of determination $\left(\mathbf{R}^{2}\right)$ was used for comparison purposes because tests that included only the intercept and regression on PA had 2 degrees of freedom, whereas predictions with an intercept and regressions on both DGV and PA had 3 degrees of freedom. Genomic PTA (GPTA) was 
Table 1. Adjusted coefficients of determination $\left(\mathrm{R}^{2}\right)^{1}$ and $P$-values for regression of deregressed evaluations on genomic PTA (GPTA) derived from individual breed SNP effects and GPTA derived from all breeds combined SNP effects (all-breed, method 2)

\begin{tabular}{|c|c|c|c|c|c|c|c|c|}
\hline \multirow[b]{2}{*}{ Predicted trait } & \multicolumn{2}{|c|}{$\begin{array}{l}\text { Holstein } \\
\text { GPTA }\end{array}$} & \multicolumn{2}{|c|}{$\begin{array}{l}\text { Jersey } \\
\text { GPTA }\end{array}$} & \multicolumn{2}{|c|}{$\begin{array}{l}\text { Brown Swiss } \\
\text { GPTA }\end{array}$} & \multirow{2}{*}{$\begin{array}{c}\begin{array}{c}\text { Parent } \\
\text { average }\end{array} \\
\mathrm{R}^{2}\end{array}$} & \multirow{2}{*}{$\begin{array}{r}\begin{array}{r}\text { All- } \\
\text { breed }\end{array} \\
\mathrm{R}^{2}\end{array}$} \\
\hline & $P$-value & $\mathrm{R}^{2}$ & $P$-value & $\mathrm{R}^{2}$ & $P$-value & $\mathrm{R}^{2}$ & & \\
\hline \multicolumn{9}{|c|}{ Holstein $(\mathrm{n}=2,507)$} \\
\hline Milk yield & $<0.001$ & 0.50 & $<0.001$ & 0.31 & 0.370 & 0.31 & 0.30 & 0.46 \\
\hline Fat yield & $<0.001$ & 0.48 & $<0.001$ & 0.25 & $0.038^{*}$ & 0.24 & 0.24 & 0.45 \\
\hline Protein yield & $<0.001$ & 0.50 & 0.297 & 0.31 & 0.200 & 0.31 & 0.31 & 0.47 \\
\hline $\mathrm{DPR}^{3}$ & $<0.001$ & 0.46 & 0.058 & 0.41 & 0.495 & 0.41 & 0.41 & 0.46 \\
\hline \multicolumn{9}{|l|}{ Jersey $(\mathrm{n}=413)$} \\
\hline Milk yield & $<0.001$ & 0.50 & $<0.001$ & 0.55 & 0.148 & 0.49 & 0.49 & 0.52 \\
\hline Fat yield & 0.005 & 0.39 & $<0.001$ & 0.48 & 0.331 & 0.38 & 0.38 & 0.44 \\
\hline Protein yield & 0.685 & 0.44 & $<0.001$ & 0.49 & 0.829 & 0.44 & 0.44 & 0.47 \\
\hline PL & 0.042 & 0.27 & $<0.001$ & 0.31 & $0.004^{*}$ & 0.27 & 0.26 & 0.29 \\
\hline \multicolumn{9}{|c|}{ Brown Swiss $(\mathrm{n}=185)$} \\
\hline Fat yield & 0.150 & 0.02 & 0.750 & 0.02 & 0.001 & 0.09 & 0.02 & 0.13 \\
\hline Protein yield & 0.258 & 0.10 & 0.872 & 0.09 & 0.086 & 0.10 & 0.09 & 0.13 \\
\hline $\mathrm{PL}$ & 0.034 & 0.41 & 0.380 & 0.40 & 0.001 & 0.42 & 0.40 & 0.43 \\
\hline SCS & 0.003 & 0.34 & 0.337 & 0.31 & 0.001 & 0.42 & 0.32 & 0.41 \\
\hline DPR & 0.267 & 0.42 & 0.137 & 0.43 & 0.001 & 0.49 & 0.42 & 0.48 \\
\hline
\end{tabular}

${ }^{1}$ Adjusted to account for adding variables into the model.

${ }^{2}$ Productive life.

${ }^{3}$ Daughter pregnancy rate.

*Indicates a negative partial regression on the direct genomic value.

defined as the sum of the intercept, the PA, and the DGV times the respective partial regressions.

The traits investigated using methods 1 and 2 were milk yield, fat yield, protein yield, productive life, SCS, and daughter pregnancy rate. Conformation traits and net merit were not investigated because conversions from within-breed to all-breed scale were not available as breeds differ in traits included in the overall index such as calving traits. Because of the intensive computation time, only protein yield was tested for method 3 .

\section{RESULTS AND DISCUSSION}

Results for method 1 (using another breed's SNP estimates) from validation regressions are compared with the traditional PA and within-breed GPTA in Table 1. In all cases, the within-breed GPTA produced a higher accuracy than the PA; this was the expected result and has been documented in the literature (Harris and Johnson, 2010; Wiggans et al., 2010). The Holstein breed had a larger population and had a larger increase in $\mathrm{R}^{2}$, which was also the expected result. A slightly surprising result was that the $\mathrm{R}^{2}$ for $\mathrm{PA}$ of the production traits for Brown Swiss were very low (0.02-0.09). This may be due to the sample and small number of
Brown Swiss validation bulls. It is partially due to using an adjusted $R^{2}$ value, which decreases the $R^{2}$ slightly. Additionally, evaluations of cows were used in the predictor set without any adjustment to their yield traits, whereas Wiggans et al. (2011) later introduced cow adjustments to the GPTA and PA. The combination of these could have caused the low accuracy of using PA for predictions for yield traits in the Brown Swiss.

Only 9 of the 36 tests showed significance $(P<0.05)$ when using another breed's SNP solutions to predict within-breed performance. Milk and fat yield predictions were significant for both Holstein and Jersey when using SNP estimates from the reciprocal breed. This result was not that surprising because DGAT1 has been shown to have a large effect on those traits for Holsteins and Jerseys (Spelman et al., 2002). We did not find the same effect on those traits for Brown Swiss, but Winter et al. (2002) documented that the $D G A T 1$ allele is present albeit at a low frequency in Brown Swiss. Even though effects for milk and fat in the Holsteins and Jerseys were significant, correlations between DGV computed using SNP effects from different breeds were not high. These correlations were $<0.30$ for all traits tested, and only 0.07 for milk when DGV for Jersey validation animals were computed us- 
Table 2. Product moment correlations between within-breed direct genomic values (DGV) and all-breed and multibreed DGV using validation bulls for yield traits

\begin{tabular}{|c|c|c|c|c|c|c|}
\hline \multirow[b]{2}{*}{ Trait } & \multicolumn{3}{|c|}{ Method 2 (all breeds) } & \multicolumn{3}{|c|}{$\begin{array}{l}\text { Method } 3 \text { (multibreed) } \\
\text { Correlation level }=0.30\end{array}$} \\
\hline & $\begin{array}{c}\text { Holstein } \\
(\mathrm{n}=2,507)\end{array}$ & $\begin{array}{c}\text { Jersey } \\
(\mathrm{n}=413)\end{array}$ & $\begin{array}{l}\text { Brown Swiss } \\
(\mathrm{n}=185)\end{array}$ & $\begin{array}{c}\text { Holstein } \\
(\mathrm{n}=2,507)\end{array}$ & $\begin{array}{c}\text { Jersey } \\
(\mathrm{n}=413)\end{array}$ & $\begin{array}{c}\text { Brown Swiss } \\
(\mathrm{n}=185)\end{array}$ \\
\hline Milk yield & 0.921 & 0.853 & 0.842 & ${ }^{1}$ & - & - \\
\hline Fat yield & 0.904 & 0.885 & 0.855 & - & - & - \\
\hline Protein yield & 0.921 & 0.884 & 0.883 & 0.997 & 0.994 & 0.996 \\
\hline
\end{tabular}

${ }^{1}$ Only protein yield was tested for the multibreed method.

ing Jersey or Holstein SNP effects, for example. These findings are consistent with those found by Hayes et al. (2009), in which Holstein and Jersey had poor correlations when the data were trained in the opposite breed only. In 2 cases, the correlations between DGV were slightly negative (results not shown). In all cases, the within-breed GPTA had a higher $\mathrm{R}^{2}$ than that using SNP effects from another breed. This is consistent with literature (Hayes et al., 2009; Pryce et al., 2011).

Results for method 2 are also given in Table 1 . The across-breed GPTA were significant $(P<0.05)$ for all the traits tested in all the breeds compared with PA alone. However, the across-breed GPTA were not more accurate than within-breed GPTA for the traits in Holsteins, and this is consistent with what others have found (Hayes et al., 2009; Pryce et al., 2011). The across-breed GPTA were not as accurate as the withinbreed GPTA in Jerseys for yield and productive life, but were equal for daughter pregnancy rate and SCS, which could be a function of the low heritability of those traits. The Brown Swiss across-breed GPTA had a higher accuracy than the within-breed GPTA for yield traits and productive life; however, daughter pregnancy rate and SCS were higher in the within-breed model. This is most likely a function of the limited number of predictor animals in the Brown Swiss data set.

The correlations between the within-breed and across-breed DGV for yield traits are in Table 2. The correlations ranged from 0.842 to 0.921 for all breeds. The Holsteins tended to have higher correlations than the other 2 breeds. This was not surprising because the Holsteins made up $74 \%$ of the training population and would have more influence on the SNP solutions.

The results for the 3 levels of correlation for method 3 (multibreed) are in Table 3. The among-breed SNP correlation parameter of 0.30 provided the highest $R^{2}$ of the 3 correlations tested. With a correlation of only 0.30 , the maximum reliability contributed by another breed would be $0.30^{2}=0.09$. Optimization of the correlation could result in slightly higher accuracy, and optimal correlations for each breed pair could also result in higher accuracy in a multibreed national genomic evaluation. Different correlations between different breeds and for different traits could be used, analogous to defining specific heterosis instead of general heterosis in a traditional all-breed model. Makgahlela et al. (2011) presented variance component estimation that could be used for this procedure.

Computational demands differed between the methods. Computational costs for method 3 (multibreed) were about 3 times the cost of the Holstein withinbreed analysis and were the highest of the methods tested. The computational costs from method 2 were about the same as the combined computational costs from computing genomic evaluations for each of the 3 breeds separately.

Comparisons of method 3 with the other methods for protein yield are in Table 4. Method 3 (multibreed, using a correlation of 0.30 ) resulted in the highest $R^{2}$ for Holsteins and Jerseys and the second highest for Brown Swiss. The increases in $\mathrm{R}^{2}$ above the withinbreed $\mathrm{R}^{2}$ were relatively small $(\leq 0.01)$. Because gains in $\mathrm{R}^{2}$ were small and computational demands high, additional traits and correlation levels were not tested. A nice feature of method 3 is the high correlation $(>0.99)$ of multibreed and within-breed DGV as shown in Table 2. Correlations were much lower (0.84 to 0.92 ) between method 2 and within-breed DGV because SNP effects had to be shared by all breeds. Method 3 also prevented data from the largest breed from dominating the smaller breeds. The method 3 results were more favorable than those reported by Makgahlela et al. (2011), who found low reliabilities with the multitrait

Table 3. Effect of assumed correlation parameter on adjusted coefficients of determination for multibreed genomic evaluation of protein yield

\begin{tabular}{lccc}
\hline & \multicolumn{3}{c}{ Correlation level } \\
\cline { 2 - 4 } Breed & 0.20 & 0.30 & 0.55 \\
\hline Holstein & 0.50 & 0.51 & 0.50 \\
Jersey & 0.49 & 0.49 & 0.49 \\
Brown Swiss & 0.11 & 0.11 & 0.11 \\
\hline
\end{tabular}


Table 4. Adjusted coefficients of determination using traditional and 3 methods of genomic evaluation for protein yield

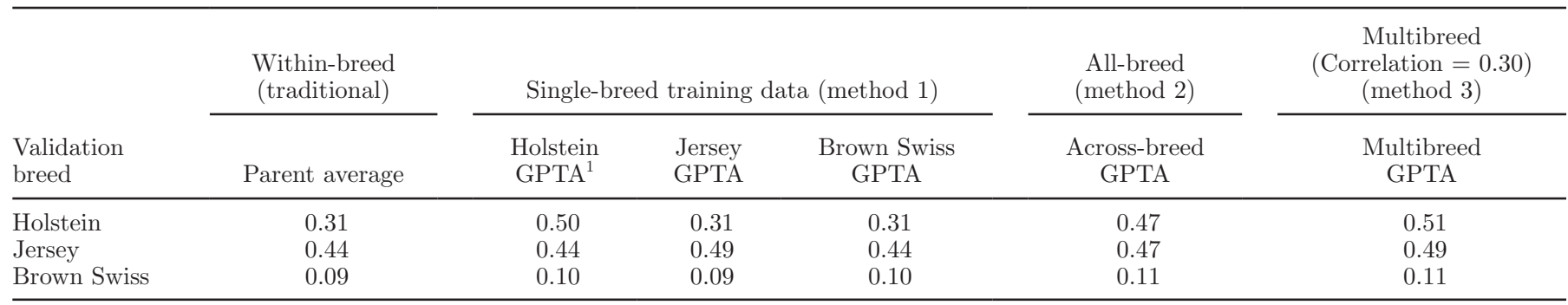

${ }^{1}$ Genomic PTA.

model in Nordic Red dairy cattle, which could be due to the different population structures. Higher density chips should increase SNP correlations and reliability of multibreed evaluations, even though early tests in New Zealand (Harris et al., 2011) did not obtain reliability gains.

\section{CONCLUSIONS}

Using another breed's SNP effects alone did not improve predictions of future performance of bulls from the other breeds. The smaller breeds (those with fewer observations) gained the most from using all the breeds in a combined genomic evaluation. The multitrait method did increase the accuracy slightly; however, computational demands also increased. For populations with crossbred animals mixed with the purebreds, the implementation of a combined population training set or a multitrait approach would be very appealing; however, not much demand for that exists yet in the current US dairy industry. A denser SNP panel could increase the gains in accuracy for a multibreed genomic evaluation using purebred dairy cattle.

\section{ACKNOWLEDGMENTS}

The authors thank G. R. Wiggans (Animal Improvement Programs Laboratory, ARS, USDA, Beltsville, MD) for help with assembling the genotype file.

\section{REFERENCES}

Cole, J. B., R. C. Goodling Jr., G. R. Wiggans, and P. M. VanRaden. 2005. Genetic evaluation of calving ease for Brown Swiss, Jersey, and Holstein bulls from purebred and crossbred calvings. J. Dairy Sci. 88:1529-1539.

de Roos, A. P. W., B. J. Hayes, R. J. Spelman, and M. E. Goddard. 2008. Linkage disequilibrium and persistence of phase in HolsteinFriesian, Jersey and Angus cattle. Genetics 179:1503-1512.

Harris, B. L., F. E. Creagh, A. M. Winkleman, and D. L. Johnson. 2011. Experiences with the Illumina high density bovine beadchip. Interbull Bull. 44:3-7.

Harris, B. L., and D. L. Johnson. 2010. Genomic predictions for New Zealand dairy bulls and integration with national genetic evaluation. J. Dairy Sci. 93:1243-1252.
Hayes, B. J., P. J. Bowman, A. C. Chamberlain, K. Verbyla, and M. E. Goddard. 2009. Accuracy of genomic breeding values in multibreed dairy cattle populations. Genet. Sel. Evol. 41:51.

Kizilkaya, K., R. L. Fernado, and D. J. Garrick. 2010. Genomic prediction of simulated multibreed and purebred performance using observed fifty thousand single nucleotide polymorphism genotypes. J. Anim. Sci. 88:544-551.

Makgahlela, M. L., E. A. Mäntysaari, I. Strandén, M. Koivula, M. J. Sillanpää, U. S. Nielsen, and J. Juga. 2011. Across-breed multitrait random regression genomic predictions in the Nordic Red dairy cattle. Interbull Bull. 44:42-46.

Pryce, J. E., B. Gredler, S. Bolormaa, P. J. Bowman, C. Egger-Danner, C. Fuerst, R. Emmerling, J. Sölkner, M. E. Goddard, and B. J. Hayes. 2011. Short communication: Genomic selection using a multi-breed, across-country reference population. J. Dairy Sci. 94:2625-2630.

Snelling, W. M., L. A. Kuehn, R. M. Thallman, J. W. Keele, and G. L. Bennett. 2009. Genomic heritability of beef cattle growth. J. Anim. Sci. 87(E-Suppl. 2):396. (Abstr.)

Spelman, R. J., C. A. Ford, P. McElhinney, G. C. Gregory, and R. G. Snell. 2002. Characterization of the DGAT1 gene in the New Zealand dairy population. J. Dairy Sci. 85:3514-3517.

Toosi, A., R. L. Fernando, and J. C. M. Dekkers. 2010. Genomic selection in admixed and crossbred populations. J. Anim. Sci. 88:32-46.

VanRaden, P. M. 2008. Efficient methods to compute genomic predictions. J. Dairy Sci. 91:4414-4423.

VanRaden, P. M., K. M. Olson, G. R. Wiggans, J. B. Cole, and M. E. Tooker. 2011. Genomic inbreeding and relationships among Holsteins, Jerseys, and Brown Swiss. J. Dairy Sci. 94:5673-5682.

VanRaden, P. M., and P. G. Sullivan. 2010. International genomic evaluation methods for dairy cattle. Genet. Sel. Evol. 42:7.

VanRaden, P. M., M. E. Tooker, J. B. Cole, G. R. Wiggans, and J. H. Megonigal Jr. 2007. Genetic evaluations for mixed-breed populations. J. Dairy Sci. 90:2434-2441.

Wiggans, G. R., T. A. Cooper, P. M. VanRaden, and J. B. Cole. 2011. Technical note: Adjustment of traditional cow evaluations to improve accuracy of genomic predictions. J. Dairy Sci. 94:61886193.

Wiggans, G. R., T. A. Cooper, P. M. VanRaden, K. M. Olson, and M. E. Tooker. 2012. Use of the Illumina Bovine3K BeadChip in dairy genomic evaluation. J. Dairy Sci. 95:1552-1558.

Wiggans, G. R., P. M. VanRaden, L. R. Bacheller, M. E. Tooker, J. L. Hutchison, T. A. Cooper, and T. S. Sonstegard. 2010. Selection and management of DNA markers for use in genomic evaluation. J. Dairy Sci. 93:2287-2292

Winter, A., W. Krämer, F. A. O. Werner, S. Kollers, S. Kata, G. Durstewitz, J. Buitkamp, J. E. Womack, G. Thaller, and R. Fries. 2002. Association of a lysine-232/alanine polymorphism in a bovine gene encoding acyl-CoA:diacylglycerol acyltransferase ( $D G A T$ 1) with variation at a quantitative trait locus for milk fat content. Proc. Natl. Acad. Sci. USA 99:9300-9305. 